Mini Review

\title{
Research Progress of Magnesium Anode Materials and Their Applications in Chemical Power Sources
}

\author{
Dong Jia ${ }^{1}$, Fan Liu ${ }^{1}$, DongZi Yang ${ }^{1}$,Wei Wang ${ }^{1,2, *}$ \\ ${ }^{1}$ School of Chemical Engineering and Technology, Tianjin University, Tianjin, China \\ ${ }^{2}$ Key Laboratory of Metal Fuel Cell of Sichuan Province, Sichuan, China \\ *E-mail: wangweipaper@163.com
}

doi: $10.20964 / 2020.10 .16$

Received: 27 May 2020 / Accepted: 1 August 2020 / Published: 31 August 2020

With the growing demand for energy, it has become a topic of constant concern to find a new and environmentally friendly material for chemical energy supply. Magnesium, in addition to being a structural metal, is also a desirable and promising anode material used for chemical power supplies. This metal shows favorable characteristics such as highly negative electrode potential, high theoretical specific charge capacity and high theoretical energy density when used as anode materials. Its abundance on the earth and environmental friendliness also make magnesium more suitable for widespread use. However, there still exist several inherent disadvantages like product adhesion, voltage hysteresis, negative difference effect and self-discharge, which adversely affect and seriously restrict the use and development of magnesium as an anode material. In this paper, the research progress and applications of magnesium anode materials in recent years are reviewed in detail, the methods to improve the electrochemical performance and corrosion resistance of magnesium anodes are systematically introduced and the development trend of magnesium anode materials is prospected.

Keywords: magnesium anode, anodic efficiency, discharge activity, self-corrosion, first-principles

\section{FULL TEXT}

(C) 2020 The Authors. Published by ESG (www.electrochemsci.org). This article is an open access article distributed under the terms and conditions of the Creative Commons Attribution license (http://creativecommons.org/licenses/by/4.0/). 